\title{
ALGUNS LIMITES E POSSIBILIDADES DA PRÁTICA PEDAGÓGICA NO CONTEXTO ESCOLAR
}

\author{
Adriana Regina de Jesus Santos ${ }^{1}-$ \\ Claudia Chueire de Oliveira ${ }^{2}$ \\ Nathalia Martins ${ }^{3}$ \\ Rogério da Costa ${ }^{4}$ \\ Hélio José Luciano ${ }^{5}$
}

\section{RESUMO}

O presente texto tem como finalidade identificar e analisar a concepção dos docentes em relação aos principais aspectos que interferem de maneira positiva e negativa na prática pedagógica, levando em consideração o cotidiano escolar. Desta maneira, para este estudo utilizaram-se pressupostos da abordagem qualitativa, amparando-se no método dialético. Assim, a pesquisa bibliográfica, documental e de campo compõem o conjunto de procedimentos investigativos. Outro ponto relevante é a compreensão referente aos limites da práxis pedagógica, considerando a relação entre o pensar e o construir de novas possibilidades referentes ao trabalho docente peculiar ao contexto em que está inserido. Assim, por meio deste estudo, constatou-se que torna-se imprescindível trabalhar com o pensar e o repensar das concepções sobre a prática docente, relacionando-a com sua construção social, a qual é permeada de ideologias, valores e relações de poder que compõem o imaginário de uma determinada sociedade.

Palavras-chave: Prática Pedagógica; Cotidiano Escolar; Ação do Professor

\section{SOME LIMITS AND POSSIBILITIES OF EDUCATIONAL PRACTICE IN SCHOOL CONTEXT}

\begin{abstract}
The purpose of this text is to identify and analyze teachers' conception in relation to the most important aspects that interfere in a positive and negative way in pedagogical practice, related to the everyday school. In this way, for this study we used assumptions of the qualitative approach, supported by the dialectic method. Therefore, bibliographical documentary and field research comprise the set of investigative procedures. Another relevant fact is the understanding of the limits of pedagogical praxis, considering the relation between thinking and building of new possibilities about teachers' work, singular to the context in which it is inserted. Thereby, this study found that is essential to work with thinking and rethinking of the conceptions about the teachers' practice, relating them with the social construction which is permeated of ideologies, values and relations of power which compound the imaginary of a particular society.
\end{abstract}

Keywords: Pedagogical practice; School routine; Teacher action 


\section{Introdução}

As constantes modificações ocorridas na sociedade, tais como o avanço da ciência e da tecnologia, a ampliação das informações, a valorização da economia e as alterações nas políticas sociais, entre outros aspectos, vão refletir diretamente no contexto escolar, visto que influenciam nas concepções adotadas pela escola, ou seja, no papel dos professores, na metodologia, no currículo e no que se refere ao papel do aluno em sala de aula, exigindo diferentes posturas e atitudes em relação à forma de aprender e no que tange à ação docente na forma de ensinar. A esse respeito, Costa (1995, p. 189) afirma que

[...] não podemos deixar de reconhecer, hoje, a incidência de consideráveis modificações operadas no mundo do trabalho pela sofisticação dos mecanismos do capitalismo, o que é registrado mesmo por teóricos de orientação marxista. O surgimento de um amplo espectro de atividades burocráticas e de prestações de serviços, e as alterações no interior de práticas ocupacionais reconhecidas e tradicionais, tem produzido mudanças nas relações de trabalho e na estrutura de classes [...].

Assim, exige-se que o professor exerça a função de mediador, uma vez que pode possibilitar condições de participação do aluno em sala de aula. Contribuindo com esta reflexão, Luckesi (1993, p. 115) expressa que

[...] educador é aquele que, tendo adquirido o nível de cultura necessário para o desempenho de sua atividade, dá direção ao ensino e aprendizagem. Ele assume o papel de mediador entre a cultura elaborada, acumulada e em processo de acumulação da humanidade.

Entretanto, a sociedade contemporânea exige para além destes elementos, isto é, apresenta o exercício docente, atrelado a um contexto específico, o qual determina um perfil profissional " $[. .$.$] de caráter polivalente, empreendedor e aberto a mudanças. No conceito de$ polivalência, podemos dizer que o trabalhador deve agora ser mais generalista do que especialista" (CHERMONT, 2006, p. 1).

Por meio desta afirmação, percebe-se que o professor com este "novo perfil" pode atuar em diferentes instâncias, pois é generalista, porém, ao realizar essas atribuições, tornase sobrecarregado, atarefado com diversas funções a cumprir, as quais acabam $o$ "engolindo" durante o cotidiano e massacrando qualquer expectativa referente ao trabalho docente. Assim, ao refletir sobre a polivalência docente, percebe-se que ela está atrelada à rotina que permeia a sociedade.

Vista sob um certo ângulo, a vida cotidiana é em si o espaço modelado (pelo Estado e pela produção capitalista) tornando o homem em robô: um robô capaz de consumismo dócil e voraz, de eficiência produtiva e que abdicou de sua condição de sujeito, cidadão (NETTO; FALCÃO, 1989, p. 19).

Isto posto, ao receber o rótulo de "profissional polivalente", o professor precisa "correr contra o tempo" para que consiga executar todas as funções, tornando-se assim um 
profissional esvaído, com condições de trabalho degradantes. Ressalta-se também que, com este ciclo do cotidiano, o professor percebe-se como único responsável pelo sucesso ou fracasso do trabalho realizado.

Nessa perspectiva, a realidade desse "professor polivalente" se assemelha com os escritos de Gramsci (1975) sobre a organicidade dos novos intelectuais, no qual enalteciam que a "neutralidade" e o seu distanciamento, na verdade, os tornavam incapazes de compreender o conjunto do sistema da produção e das lutas hegemônicas, enaltecendo o isolamento entre o trabalho do homem e o contexto em que o mesmo está inserido, afirmando uma visão fragmentada que dificulta o pensar significativamente sobre aquilo que realiza.

Levando em consideração tais pressupostos, pretendemos discutir esses aspectos, pois acreditamos que o "trabalho docente não consiste apenas em cumprir ou executar uma tarefa, mas é também a atividade de pessoas que não podem trabalhar sem dar um sentido ao que fazem [...]" (TARDIF, 2005, p. 38), necessitando, dessa maneira, de um olhar reflexivo sobre a prática pedagógica.

\section{Um Olhar para a Prática Pedagógica}

Tendo em vista o contexto sócio, político, cultural e econômico da sociedade contemporânea, o próprio professor não tem compreendido ao certo qual é o princípio que embasa o ser e o fazer docente. Segundo Sacristán (1995), para que ocorra uma compreensão sobre a profissionalidade docente, é preciso que se amplifique o conceito de prática educativa, devendo ser percebida de forma mais abrangente, e não apenas pela prática didática não contextualizada.

Assim, essa prática não pode acontecer de maneira desconexa do contexto específico em que adentra, isto é, na sociedade em que ela está inserida; portanto, para tal reflexão, é necessário considerar que, consequentemente, essa instância vem implicar no contexto escolar, e posteriormente na prática pedagógica.

Simultaneamente, tais aspectos do contexto social exigem do docente novas formas de direcionar sua prática, pois "a profissão docente é uma pratica educativa, é uma forma de intervir na realidade social mediante a educação" (PIMENTA; ANASTASIOU, 2008, p. 178). E, sendo a educação uma prática social implicada na relação teoria e prática, "é nosso dever, como educadores, a busca de condições necessárias a sua realização" (VEIGA, 1989, p. 16).

Nesse sentido, para entendermos a prática docente, faz-se necessário compreender o trabalho educativo dessa categoria, a fim de perceber a essência do fazer docente. Para isso, o docente tem que se conscientizar de que

[...] a realidade não pode ser modificada, senão quando o homem descobre que é modificável e que ele pode fazê-lo. É preciso, portanto, fazer desta conscientização o primeiro objetivo de toda a educação: antes de tudo provocar uma atitude crítica, de reflexão, que comprometa a ação (FREIRE, 1979, p. 40).

Diante disso, compreende-se que o professor necessita trabalhar com a reflexão de expectativas e perspectivas, as quais exigem dele uma nova forma de pensar sua prática em sala de aula, onde o docente possa construir o sentimento de pertença, inclusive no repensar seu real papel na sociedade, visando ao contexto em que atua. 
Dessa maneira, é necessário um olhar diferenciado para a prática pedagógica, pois muitas vezes essas informações advindas do contexto social chegam para o professor de forma fragmentada, fazendo com que olhe o mundo de forma linear, e não de maneira ampla, o que possibilitaria a totalidade da visão de mundo; assim, "faz-se necessário uma reavaliação das relações entre escola e sociedade, entre informação e conhecimento, entre fontes de informação provida pelos meios de comunicação e o trabalho escolar realizado pelo professor" (LIBÂNEO, 1998, p. 76).

Isto posto, o olhar fragmentado em relação à sociedade e à educação conduzem o docente a uma prática inibida, na qual o atuar no mundo torna-se impreciso, surgindo, dessa maneira, o medo e a insegurança. Conforme o pensamento de Bauman (2001, p. 243), a sociedade contemporânea nos leva a "viver entre uma multidão de valores, normas e estilos de vida em competição, sem uma garantia firme e confiável de estarmos certos".

Portanto, pode-se perceber que o cenário sócio-político-econômico-cultural e tecnológico apresenta desafios e indagações no que diz respeito à prática pedagógica, pois, nesse procedimento de transformação social, percebe-se que acontecem alterações significativas que culminam em uma análise parcial do homem, resultando na maneira como ele pode compreender o contexto do seu trabalho; em suma, dando-lhe características comuns e padronizadas imputadas pela sociedade.

Percebe-se, dessa forma, que a prática pedagógica necessita ser problematizada, pois está atrelada a um contexto propício para a proliferação de concepções que vão sendo construídas e modificadas com o passar dos tempos, idealizadas em nossas relações sociais do dia a dia.

Para tanto, ao pensar criticamente a prática pedagógica do professor tendo em vista o contexto da sociedade contemporânea, faz-se necessário analisar os aspectos presentes e que interferem no cotidiano escolar.

\section{A educação e o cotidiano como espaço e tempo de ressignificação}

$\mathrm{Na}$ tentativa de compreender a educação no contexto da sociedade contemporânea, bem como o cotidiano escolar, foi necessário realizar uma pesquisa de campo em um colégio estadual situado no munícipio de Londrina, Estado do Paraná. Para tanto, utilizou-se como metodologia pressupostos da abordagem qualitativa, tendo como parâmetro o método dialético. Segundo Konder, neste método

[...] o conhecimento é totalizante e a atividade humana, em geral, é um processo de totalização, que nunca alcança uma etapa definitiva e acabada. [...] Qualquer objeto que o homem possa perceber ou criar é parte de um todo. Em cada ação empreendida, o ser humano se defronta, inevitavelmente, com problemas interligados. Por isso, para encaminhar uma solução para os problemas, o ser humano precisa ter uma certa visão de conjunto deles: é a partir da visão do conjunto que a gente pode avaliar a dimensão de cada elemento do quadro. Se não enxergarmos o todo, podemos atribuir um valor exagerado a uma verdade limitada (transformando-a em mentira), prejudicando a nossa compreensão de uma verdade mais geral (KONDER, 2008, p. 35).

Faz-se necessário ressaltar que a metodologia desta pesquisa tem como base a abordagem qualitativa; para tanto, algumas características propostas por Bogdan e Biklen (1994, p. 47-51) particularizam este estudo, por entender que 
[...] a fonte direta de dados é o ambiente natural, constituindo o investigador o instrumento principal; [...] a investigação qualitativa é descritiva; [...] os investigadores qualitativos interessam-se mais pelo processo do que simplesmente pelos resultados; [...] os investigadores qualitativos tendem a analisar os seus dados de forma indutiva; [...] o significado é de importância vital na abordagem qualitativa [...].

Ou seja, nesta perspectiva, é necessária uma compreensão maior sobre o objeto de investigação, tendo como parâmetro nesta abordagem o processo, e não simplesmente o resultado final; sendo assim, o princípio fundante é identificar os significados visíveis e latentes que são perceptíveis a uma atenção sensível (CHIZZOTTI, 2006).

Outro fator importante relacionado à abordagem qualitativa refere-se à necessidade de o pesquisador estar amparado "[...] numa fundamentação teórica geral, o que significa revisão aprofundada da literatura em torno do tópico em foco" (TRIVIÑOS, 1990, p. 131).

Portanto, o conjunto de procedimentos investigativos utilizados para compreender a concepção docente no que se refere aos principais fatores que interferem de maneira positiva e negativa na prática pedagógica do professor em sala de aula foram formados pela pesquisa bibliográfica, análise documental, questionário e entrevista semiestruturada, as quais foram aplicadas em um colégio estadual, localizado na cidade de Londrina.

Sobre a pesquisa bibliográfica na produção de conhecimentos, entendemos que sua função não se reduz apenas a explicitar as ideias de autores distintos, mas sim exigir do pesquisador

[...] a produção de argumentações sobre o tema, oriundas de interpretação própria, resultado de um estudo aprofundado sobre o assunto. Concordar, discordar, discutir, problematizar os temas à luz das ideias dos autores lidos são os procedimentos dessa modalidade de pesquisa (TOZONI-REIS, 2009, p. 27).

A análise documental, referente ao Projeto Político Pedagógico foi de suma importância, pois foi possível identificar a organização pedagógica pensada pela comunidade escolar, o que possibilitou entender uma pouco mais sobre "a organização da educação ou do ensino no cotidiano de uma escola (TOZONI-REIS, 2009, p. 30).

Em relação à escolha pela utilização do questionário, ela se deu por ser um instrumento composto por questões: claras, concisas e bem estruturadas, a serem respondidas sem a presença do pesquisador para que este não exercesse influência sobre os respondentes (LAVILLE; DIONE, 1999). Os professores do referido colégio, aos quais o questionário foi aplicado, apresentaram uma faixa etária entre 22 e 62 anos, com um total de 69 docentes participando, sendo 29 pedagogos (ensino infantil), 06 professores dos anos iniciais do ensino fundamental e 21 dos anos finais, 03 do ensino profissionalizante e 10 do ensino médio.

No que diz respeito à diferença dos professores participantes, tendo em consideração os níveis de ensino, lembramos que a adesão dos profissionais na pesquisa se deu de forma aleatória, isto é, foi feito um convite para o corpo docente do colégio e trabalhamos com os professores que atenderam a nossa solicitação.

Findou-se a pesquisa de campo com a entrevista semiestruturada, que foi realizada com alguns dos professores que já haviam respondido o questionário; no intuito de esclarecer algumas indagações que ainda permeavam, a entrevista foi gravada e transcrita na íntegra, como forma de garantir fidedignidade. A pergunta norteadora para questionar os 
professores foi: Quais os principais fatores que interferem de maneira positiva e negativa no desenvolvimento do seu trabalho?

Cabe mencionar que preservamos a identidade dos participantes da pesquisa, utilizando códigos para nomeá-los: a letra "P" se refere a "professor".

Os dados coletados por meio da pesquisa de campo apontaram que, quando questionados sobre quais os principais aspectos que interferem de maneira positiva e negativa na prática pedagógica, os professores sujeitos da nossa pesquisa apresentaram diferentes percepções, dentre as quais uma mereceu atenção maior por parte da nossa pesquisa, que foi a categoria de "coisificação", na qual os docentes expressam sua prática escolar, isto é, fatores que perpassam a ação docente por meio de um discurso no qual engendram acriticamente rotinas vivenciadas na prática pedagógica. Dentro deste contexto, Kosik (1976, p. 60) relata que

O caráter coisificado da práxis, [...] significa que na manipulação já não se trata mais da obra que se cria, mas do fato de que o homem é absorvido pelo mero ocupar-se e "não pensa" na obra. O ocupar-se é o comportamento prático do homem no mundo já feito e dado; é tratamento e manipulação dos aparelhos no mundo, mas não é criação do mundo humano.

Assim, na análise das respostas, constatou-se que em suma os professores apresentam uma concepção em torno do trabalho pedagógico permeada de uma suposta compreensão de mundo resultante da herança fecunda de um grupo social, além de ser prédeterminado, pronto, e que não há reflexão a respeito desse trabalho. Pode-se perceber esta concepção quando os docentes relatam sobre os aspectos positivos do trabalho nas falas abaixo:

De maneira positiva a minha organização. Eu me organizo para poder trabalhar, gosto de tudo muito certinho, sabe?! Eu tenho um planejamento, eu sou uma ótima professora (Professor de Matemática).

De maneira positiva, principalmente o trabalho que realizo em sala de aula. Sempre quis ser professora, então acho que isso ajuda também (Professora de Português).

De maneira positiva eu vejo que é o meu trabalho, eu amo muito o que eu faço, eu faço meu planejamento, assim como a escola pede, sempre tenho minhas coisas em ordem (Professora de Português).

Positivo é o que eu faço, as aulas que eu planejo para os alunos e o próprio trabalho que realizo. E isso é muito bom (Professor de Geografia).

De positivo é a quantidade de material e informação que a gente tem hoje, isso é muito bom, para minha profissão, pelo próprio prazer de ensinar. (Professor de Química).

Com relação às respostas dos professores, podemos perceber fatos realmente positivos, pois uma das características da função docente deve ser o momento de planejar a aula, ou seja, organizar o trabalho para que esse momento esteja sempre coerente com o propósito de proporcionar a aquisição do conhecimento. Porém, quando o professor apenas percebe a si neste processo, como ficou latente nos discursos, uma visão mais ampla, que engloba o aluno, a instituição, as políticas públicas dentre outras questões, deixa de ser notada e refletida; com isso, os professores não compreendem que os conhecimentos que distinguem a maneira de ser dos elementos carecem ser entendidos de modo interligado, isto 
é, em sua totalidade. No entanto, necessitamos ter ciência de que essa visão ampla, que interliga esse conjunto de elementos com vistas à totalidade,

[...] é sempre provisória e nunca pode pretender esgotar a realidade a que ele se refere. A realidade é sempre mais rica do que o conhecimento que temos dela. Há sempre algo que escapa às nossas sínteses; isso, porém, não nos dispensa do esforço de elaborar sínteses, se quisermos entender melhor a nossa realidade (KONDER, 2008, p. 36).

Desta forma, por meio das respostas dos professores, destacam-se concepções que precisam ser mais refletidas no que tange ao que é ser positivo no trabalho docente, pois a representação dos docentes sobre o que é ser positivo faz fechar um círculo em torno do professor, como se ele fosse a razão única da educação; assim, o discurso se apresenta cristalizado socialmente e se caracteriza por ser pautado apenas em uma prática técnica e sem reflexão, pois "[...] não exige um docente profissional e até mesmo prefere um docente que domine e execute os métodos e as técnicas reputados eficazes e comprovados" (LESSARD, 2006, p. 231).

Quanto aos aspectos negativos que interferem na prática pedagógica, os professores apresentaram algumas concepções que evidenciam diversas incógnitas que perpassam a educação escolar, como aspectos relacionados a conteúdo escolar, família, tecnologia etc. De modo geral, os discursos vão ao encontro de fatores que são resultados das várias mudanças pelas quais passa a sociedade contemporânea; eles são caracterizados em algumas falas apresentadas a seguir:

O que eu acho negativo é muito conteúdo, tem muita coisa que eu tenho que trabalhar com o aluno, que está no currículo, que tá posto, só que eu acho que não precisava (Professor de Matemática).

Em relação ao discurso apresentado, entendemos que o fazer docente, no que diz respeito aos conteúdos escolares, devem caminhar em direção a um currículo acessível e flexível, em que a prática da sala de aula carece ser constantemente sustentada por uma reflexão crítica.

Desta forma, esse conteúdo não poder ser algo dado e homogêneo, isto é, não poderá ser transmitido de igual maneira a todos os sujeitos, terá que ser composto e sistematizado em consonância com as dificuldades e realidades de cada um, ou seja, o currículo e em consequência disso os conteúdos escolares necessitam contestar e dialogar constantemente acerca das necessidades sociais.

Conforme o pensamento de Sacristán e Gómez (1996, p. 155), devemos perceber o que "os homens fazem na vida real e saberemos o que deve ser o conteúdo de sua escolaridade".

Em outro discurso dos sujeitos de nossa pesquisa, ficam demonstradas preocupações que apontam para a relação que os pais sustentam com seus filhos, relação que influencia diretamente na educação escolar; segundo esse discurso, quando a criança é educada pela família sem a colocação de limites, ocasionará algumas dificuldades enfrentadas pela escola; aspectos explícitos estão na fala abaixo:

De negativo a educação das crianças dada pelos pais, por exemplo, a falta de limite, hoje em dia esse é um grande problema, enfrentado na escola (Professora de Português). 
No relato apresentado acima, fica explícito que devemos refletir que, no atual contexto social, tanto família quanto escola têm visto a complexidade do papel de cada instância, e esta é ocasionada pelas transformações socioeconômicas e culturais, influenciadas pelo constante movimento do capital. Claro que, ao analisarmos tais implicações, devemos reconhecer que essas modificações não desobrigam a família e a escola do seu papel de formadores. No entanto, pensando conforme Boechat (2003, p. 42), "Quem se perdeu não foi o jovem, foi o adulto que não está conseguindo ler a modernidade e a confunde com frieza, distanciamento, solidão, perdas".

Dentro desse panorama, o que se observa, atualmente, é uma seleção dinâmica e superficial de tipos estabelecidos de acordo com interesses econômicos ou, muitas vezes, apenas identificados e potencializados por eles e, apesar do alto nível tecnológico dos meios, dissemina padrões comportamentais de ajustamento dos indivíduos.

Neste sentido, no contexto da atual da sociedade, designada como "sociedade da informação", notam-se elementos que são constituídos e sofrem influências determinantes dos meios de comunicação, decisivos para controlar e influenciar os processos educacionais, permeando diretamente a relação com o saber. Alguns discursos transcritos a seguir, acerca de fatores negativos no trabalho docente, nos mostram essas particularidades que perpassam a educação escolar:

Eu acho a tecnologia negativa [...] pois o aluno fica o tempo todo com o celular, iPad, música e não presta atenção no que a professora tá explicando, depois vai mal na prova e não sabe por quê, é difícil viu! (Professora de Educação Física).

Como negativo é o aluno! Ele só pensa nas tecnologias e vem pra sala com vontade de ficar em casa, chega aqui só fica no celular, não se interessa por nada do que eu passo (Professor de Química).

Quanto a esses aspectos tecnológicos, muito mais que apenas demonizar, entendemos que as transformações dessa sociedade da informação solicitam igualmente um novo olhar para o ensino, mas para isso são necessários conhecimentos atualizados na educação, o que faz com que tenhamos de repensar o espaço escolar como um todo. Assim, esse espaço precisará caminhar em direção à resolução das questões concernentes a essas modificações das atitudes em sala de aula, no que diz respeito ao conhecimento e ao domínio do saber.

Dessa forma, será preciso haver um estranhamento do cotidiano, ou seja, não encararmos essas atitudes dos alunos naturalizando-as, como se isso fosse assim e pronto, sem base para mudanças. É imprescindível reeducarmos o nosso olhar. É preciso termos ciência que nossa visão da realidade está marcada por julgamentos, prenoções, sentimentos, preconceitos, que são influenciados pelas mediações da tecnologia, das escolas, das famílias, das religiões, etc. (MORAES, 2010).

Sob a égide dessa perspectiva, percebe-se que, ao enaltecer os aspectos negativos que interferem no trabalho, o professor não se observa como integrante desse contexto, situação completamente distante ao ressaltar os aspectos positivos, pois, ao se referir sobre eles, o docente coloca-se como centro da função.

Assim, percebe-se que na concepção docente referente aos pontos positivos e negativos que interferem no trabalho pedagógico está arraigado a "práxis utilitária", na qual, cotidianamente, cria

[...] o pensamento comum - em que são captados tanto a familiaridade com as coisas e o aspecto superficial das coisas quanto a técnica de 
tratamento das coisas - como forma de seu movimento e de sua existência. O pensamento comum é a forma ideológica do agir humano de todos os dias. Todavia, o mundo que se manifesta ao homem na praxis fetichizada, no tráfico e na manipulação, não é o mundo real, embora tenha a "consistência" e a "validez" do mundo real: é "o mundo da aparência" (KOSIK, 1976, p. 15).

Nesse sentido, apenas uma ampla discussão sobre a prática pedagógica pode ressignificar conceitos que confundem o fazer docente e atributos que fazem parte da função do professor, e, ao discutir conscientemente sobre tais aspectos, pode-se perceber que, ao se colocarem como protagonistas nos pontos positivos e omitirem-se nos pontos negativos, os professores estão equivocados, pois a prática pedagógica não deve ser fragmentada e a ação docente está presente em ambos os aspectos.

\section{Considerações Finais}

A presente pesquisa aponta para a necessidade de repensar a concepção sobre a prática pedagógica, visto que esses professores estão atuando em sala de aula e não conseguem ter pertencimento sobre o contexto em que adentram, pois, ao conceber pontos positivos e negativos de modo distorcido, envolto no senso comum, em que se entra e sai da sala de aula com o mesmo pensamento, existe uma probabilidade muito grande de esse professor repetir esse discurso em sua prática educativa.

Entende-se também, que essas concepções precisam ser problematizadas para que o docente compreenda que as respostas ou soluções para os problemas devem ser buscadas, sobretudo, na própria realidade empírica, nas relações que os homens desenvolvem uns com os outros.

Diante dos fatores concebidos pelos professores, compreendemos que a prática docente necessita ser constantemente refletida e repensada de forma crítica. Neste sentido, o docente necessita reler o contexto que o cerca, deparar-se com novas realidades, manter-se sempre atualizado e perceber-se como sujeito na sociedade contemporânea, a qual deve refletir sobre esse cotidiano para que ele não o massacre com interposições, pois em suma os pontos positivos e negativos que interferem no trabalho docente estão diretamente atrelados à realidade social que transcende no contexto escolar e, consequentemente, na prática pedagógica.

\section{Referências}

BAUMAN, Zigmund. Modernidade Líquida. Rio de janeiro: Jorge Zahar, 2001.

BOECHAT, Ivone. A Família no Século XXI. 2. ed. Rio de Janeiro: Reproarte, 2003.

BOGDAN, Robert; BIKLEN, Sari Knopp. Investigação Qualitativa em Educação. Porto: Porto, 1994.

COSTA, Marisa Cristina Vorraber. Trabalho docente e profissionalismo. - Porto alegre: Sulina, 1995.

CHERMONT, Gisele Salgado de. A qualidade na Gestão de Projeto de Sistema de Informação. Rio de janeiro, 2006.

CHIZZOTTI, Antônio. Pesquisa qualitativa. Petrópolis: Vozes, 2006. 
FREIRE, Paulo. Conscientização: teoria e prática da libertação: uma introdução ao pensamento de Paulo Freire. São Paulo: Cortez \& Moraes, 1979.

GRAMSCI, Antonio. Quaderni del carcere. Turim: Einaudi, 1975.

NETTO, José Paulo; FALCÃO, Maria do Carmo. Cotidiano: conhecimento e crítica. São Paulo: Cortez, 1989.

KONDER, Leandro. O que é dialética. 28. ed. São Paulo: Brasiliense, 2008.

KOSIK, Karel. Dialética do Concreto. Rio de Janeiro: Paz e Terra, 1976.

LAVILLE, Christian; DIONNE, Jean. A construção do saber: manual de metodologia da pesquisa em ciências humanas. Porto Alegre: Artmed, 1999.

LESSARD, Claude. A universidade e a formação profissional dos docentes: novos questionamentos. Educação \& Sociedade, v. 27, n. 94, p. 223-240, jan.-abr. 2006.

LIBÂNEO, José Carlos. Adeus professor, adeus professora: Novas exigências educacionais e profissão docente. São Paulo: Cortez, 1998.

LUCKESI, Cipriano Carlos. Filosofia da educação. Série formação do professor. 21. ed. São Paulo: Cortez, 1993 (Coleção Magistério $2^{\circ}$ grau).

MORAES, Amaury César. (Coord.). Sociologia: ensino médio. Brasília: Ministério da Educação, Secretaria de Educação Básica, 2010.

PIMENTA, Selma Garrido; ANASTASIOU, Léa das Graças Camargos. Docência no ensino superior. 3. ed. São Paulo: Cortez, 2008.

SACRISTÁN, José Gimeno. Consciência e acção sobre a prática como libertação profissional dos professores. In: NÓVOA, António. Profissão professor. Porto: Porto, 1995. p. 56-67.

\section{6. \\ ; GÓMEZ, Pérez. Compreender e transformar o ensino. Porto Alegre: ARTMED,}

TARDIF, Maurice. O trabalho docente: elementos para uma teoria da docência como profissão de interações humanas. Rio de Janeiro: Vozes, 2005.

TOZONI-REIS, Marília Freitas de Campos. Metodologia da Pesquisa. 2. ed. Curitiba: IESDE Brasil S.A., 2009.

TRIVIÑOS, Augusto Nibaldo Silva. Introdução à pesquisa em ciências sociais: a pesquisa qualitativa em educação. São Paulo: Atlas, 1990.

\footnotetext{
${ }^{1}$ Universidade Federal Fluminense

${ }^{2}$ Universidade Estadual de Londrina

${ }^{3}$ Universidade Estadual de Londrina

${ }^{4}$ Universidade Estadual de Londrina

${ }^{5}$ Universidade Estadual de Londrina
}

Recebido: abril/16 Aprovado: dezembro/16 